Jussi Heinonen MD, Markku Salmenperä MD, Olli Takkunen MD

\title{
Increased pulmonary artery diastolic- pulmonary wedge pressure gradient after cardiopulmonary bypass
}

In 29 patients undergoing elective coronary artery bypass grafting, the diastolic pulmonary arterial pressurepulmonary capillary wedge pressure gradient (DPAP$P(W P)$ and related haemodynamic parameters were determined before and after induction of anaesthesia, immediately after cardiopulmonary bypass $(C P B)$ and one and three hours after $C P B$. The DPAP-PCWP gradient remained unchanged after induction of anaesthesia but was significantly increased after CPB. A gradient of $5 \mathrm{mmHg}$ or grealer was observed in 16 patients after $C P B$, whereas none of the patients showed such a gradient before $C P B$. A significant correlation was found berveen the change in DPAP-PCWP and the change in pulmonary vascular resistance ( $P V R$ ). It is concluded that DPAP should not be used as a substitute of $P C W P$ in the early postbypass period without frequent confirmation of the presence of the normal small DPAP$P C W P$ gradient. Since an increase of PVR may impair right ventricular ejection, we recommend the routine measurement of DPAP-PCWP gradient in the postbypass period.

\section{Key words}

LUNG: intravascular pressures, vascular resistance; SURGERY: cardiac; MONITORING: blood pressure, pulmonary artery pressure.

From the Cardiothoracic Anaesthesia Group, Department of Anaesthesia, Helsinki University Central Hospital, Helsinki, Finland.

Address correspondence to: Dr. J. Heinonen, Dept. of Anaesthesia, Helsinki University Central Hospital, Haartmaninkatu 4, SF-00290 Helsinki 29, Finland.
Although end-diastolic pulmonary arterial pressure (DPAP) does not reflect left attial pressure (LAP) as accurately as pulmonary capillary wedge pressure (PCWP) in cardiac surgical patients, ${ }^{1-3}$ it has been recommended as a clinical estimate of left heart filling pressure in these and other cases. ${ }^{4.5}$ In the absence of tachycardia and in the presence of normal pulmonary vascular resistance (PVR), DPAP is only slightly higher ( 1 to $3 \mathrm{mmHg}$ ) than the mean PCWP. ${ }^{6}$ However, tachycardia or increased PVR are associated with a significant DPAPPCWP gradient. ${ }^{6-8}$ After cardiopulmonary bypass (CPB), heart rate is commonly increased and a temporary increase of PVR in the postbypass period has been reported. ${ }^{9}$ As we observed an increase in DPAP-PCWP gradient in occasional patients after CPB, we decided to study the effect of cardiac anaesthesia and surgery on this gradient and related parameters.

\section{Methods}

Twenty-nine patients (27 male, two female) undergoing elective coronary artery bypass grafting were randomly selected for the study. Their mean age ( \pm SEM) was $52.0 \pm 1.3 \mathrm{yr}$, weight $82.2 \pm 2.1 \mathrm{~kg}$ and ejection fraction $0.61 \pm 0.03$. No patient had valvular heart disease. Beta-adrenergic blocking drugs (27 patients) and calcium entry blockers (12 patients) were continued up to the evening before surgery. The study protocol was approved by the Ethical Committee of the institute.

Premedication was with morphine $0.2 \mathrm{mg} \cdot \mathrm{kg}^{-1}$ and scopolamine $0.006 \mathrm{mg} \cdot \mathrm{kg}^{-1}$. Intravascular catheters were inserted under local anaesthesia using one per cent lidocaine. The patients were 
anaesthetized with diazepam $0.1 \mathrm{mg} \cdot \mathrm{kg}^{-1}$ and fentanyl $75 \mu \mathrm{g} \cdot \mathrm{kg}^{-1}$ and muscle relaxation was achieved with pancuronium. When required, enflurane or halothane was administered to control the blood pressure during the surgery before the commencement of $\mathrm{CPB}$. The patients were ventilated with a mixture of oxygen and air $\left(\mathrm{F}_{1} \mathrm{O}_{2} \mathrm{O}\right.$.5) using a Servo $900 \mathrm{~B}$ ventilator which was adjusted according to $\mathrm{PaCO}_{2}$ values.

The extracorporeal CPB circuit consisted of polyvinylchloride tubing and a disposable bubble oxygenator (Shiley 100A). A 20 micron filter was used in the arterial in-flow side of the oxygenator. Blood was drained under gravity from the right atrium and inferior vena cava and returned to the aorta using a roller pump (Gambro HL10). Left ventricular venting was used in all cases. The circuit was primed with $30 \mathrm{ml} \cdot \mathrm{kg}^{-1}$ of Ringer's acetate solution. This solution or, in case of haematocrit below 0.25 , blood was added to compensate for losses during CPB. The rate of the nonpulsatile flow during the pump procedure was $2.41 \cdot \mathrm{m}^{-2}$. Oxygen at four $1 \cdot \mathrm{min}^{-1}$ was added to the oxygenator and carbon dioxide was added to maintain normocarbia as assessed by $\mathrm{PaCO}_{2}$ values uncorrected to body temperature. ${ }^{10}$ Heparinization was attained with $3 \mathrm{mg} \cdot \mathrm{kg}^{-1}$ of heparin and with increments thereafter keeping the activated clotting time over $450 \mathrm{sec}$ (Hemochron). Cardiac arrest was accomplished with cold potassium cardioplegia and topical cooling of the heart was also used. The lowest nasopharyngeal temperature during CPB was $32-33^{\circ} \mathrm{C}$. The aortic cross-clamping time was $63 \pm 4.9 \mathrm{~min}$. Upon completion of the ischaemic period, systemic rewarming to normothermia was accomplished by means of a heat exhanger. During total CPB the lungs were ventilated with two $1 \cdot \mathrm{min}^{-1}$ of the oxygen-air mixture at a rate of 10 breaths $\cdot \mathrm{min}^{-1}$ using positive end-expiratory pressure of $5 \mathrm{cmH}_{2} \mathrm{O}$.

Postoperatively, ventilation was controlled using either a Servo $900 \mathrm{~B}$ or IMV Bird ventilator. $\mathrm{FIO}_{2}$ was 0.5 and end-expiratory pressure was +5 $\mathrm{cmH}_{2} \mathrm{O}$. Dopamine at a dosage range of 2 to $8 \mu \mathrm{g} \cdot \mathrm{kg}^{-1} \cdot \mathrm{min}^{-1}$ was administered after CPB when arterial hypotension associated with normal or low cardiac output was documented.

Measurements were made in the following phases: (1) a few minutes after the insertion of intravascular catheters while the patient was breathing room air. (2) About $20 \mathrm{~min}$ after endotracheal intubation before the start of surgery. (3) Before the closure of pericardium after CPB when $3 \mathrm{mg} \cdot \mathrm{kg}^{-1}$ of protamine sulphate had been given to neutralize the effect of heparin. (4) About one hour after the termination of CPB when surgery was completed. (5) Three hours after CPB, when all patients were still unconscious.

A cannula introduced into the radial artery provided a site for the measurement of systemic arterial pressure and for sampling arterial blood. A Swan-Ganz thermodilution catheter, size 7F (Edwards Laboratories), was inserted via the right internal jugular vein and it enabled the measurement of pulmonary arterial pressure, PCWP and central venous pressure (CVP). The catheters were connected to AE 840 (AME) transducers and pressures were recorded with an ink-jet recorder (Mingograf 81, Elema-Schönander). The mid-chest level was taken as the zero reference point, and pressures were read at the end of expiration. Actual pressure curves were used for calculation of the DPAP-PCWP gradient. Mean PCWP as estimated from the curve was used for this calculation. For other purposes, the intravascular pressures were recorded as electronic means. Cardiac output (CO) was measured by the thermal dilution technique with $10 \mathrm{ml}$ of 0.9 per cent saline solution at room temperature injected at the end of expiration and using a Finnomedical cardiac output computer (model 804). CO was expressed as the mean of the values calculated from three well-formed curves. Arterial blood was analyzed immediately by an automatic blood gas analyzer (ABL 1, Radiometer).

Systemic (SVR) and pulmonary (PVR) vascular resistances were calculated using formulae:

$$
\begin{aligned}
& \text { SVR }=80 \times \frac{\text { MAP }- \text { CVP }}{\text { CO dyne } \cdot \mathrm{sec} \cdot \mathrm{cm}^{-5}} \\
& \text { PVR }=80 \times \frac{\text { MPAP }- \text { PCWP }}{\text { CO dyne } \cdot \mathrm{sec} \cdot \mathrm{cm}^{-5}}
\end{aligned}
$$

The statistical computations were performed using the BMDP software by UCLA. " Analysis of variance (ANOVA) for repeated measurements followed by the paired t-test with the Bonferroni allowance for multiple comparisons was used to assess the significance of the changes over time. The t-test for two independent samples was used to compare the patients who did or did not receive 
TABLE Mern values ( \pm SEM) of the haemodynamic parameters at the five stages of the study

\begin{tabular}{|c|c|c|c|c|c|}
\hline & Awake & $\begin{array}{l}\text { After } \\
\text { induction }\end{array}$ & $\begin{array}{l}\text { Immediately } \\
\text { after } C P B\end{array}$ & I hr affer $C P B$ & $3 \mathrm{hr}$ after $C P B$ \\
\hline MAP (mmHg) & $98.3 \pm 2.2^{*}$ & $89.3 \pm 3.3$ & $76.6 \pm 2.2 \dagger$ & $78.9 \pm 1.9 *$ & $86.9 \pm 2.4$ \\
\hline MPAP $(\mathrm{mmHg})$ & $15.8 \pm 0.6 \dagger$ & $13.8 \pm 0.7$ & $15.4 \pm 0.6$ & $15.9 \pm 0.7$ & $16.4 \pm 0.5^{*}$ \\
\hline DPAP $(\mathrm{mmHg})$ & $10.7 \pm 0.7 \ddagger$ & $8.0 \pm 0.6$ & $11.1 \pm 0.6 \dagger$ & $11.7 \pm 0.7 \ddagger$ & $12.3 \pm 0.5 \ddagger$ \\
\hline PCWP (mmHg) & $9.2 \pm 0.6 \neq$ & $6.3 \pm 0.7$ & $7.5 \pm 0.6$ & $7.8 \pm 0.6$ & $8.1 \pm 0.6^{*}$ \\
\hline DPAP-PCWP $\left(\mathrm{mmH}_{\mathrm{g}}\right)$ & $1.4 \pm 0.3$ & $1.7 \pm 0.2$ & $3.7 \pm 0.4 \ddagger$ & $3.9 \pm 0.3 \ddagger$ & $4.1 \pm 0.4 \ddagger$ \\
\hline CVP (mmHg) & $5.0 \pm 0.5$ & $4.1 \pm 0.4$ & $7.0 \pm 0.5 \ddagger$ & $8.1 \pm 0.6 \neq$ & $8.0 \pm 0.5 \ddagger$ \\
\hline $\operatorname{CO}\left(1 \cdot \min ^{-1}\right)$ & $5.7 \pm 0.2 \ddagger$ & $4.9 \pm 0.2$ & $4.9 \pm 0.2$ & $4.2 \pm 0.2^{*}$ & $4.5 \pm 0.2$ \\
\hline HR (beat $\mathrm{min}^{-1}$ ) & $62.7 \pm 1.5$ & $61.6 \pm 1.8$ & $91.8 \pm 2.2 \ddagger$ & $92.8 \pm 2.1 \ddagger$ & $88.4 \pm 2.4 \ddagger$ \\
\hline SVR $\left(\right.$ dyne $\left.\cdot \sec \cdot \mathrm{cm}^{-5}\right)$ & $1354 \pm 58$ & $1447 \pm 64$ & $1171 \pm 48 \dagger$ & $1404 \pm 73$ & $1470 \pm 72$ \\
\hline PVR (dyne $\cdot \sec \cdot \mathrm{cm}^{-5}$ ) & $97.2 \pm 8.2$ & $113.0 \pm 6.3$ & $141.9 \pm 9.6^{*}$ & $154.3 \pm 10.7 \dagger$ & $158.7 \pm 12.4^{*}$ \\
\hline $\mathrm{PaCO}_{2}(\mathrm{kPa})$ & $5.4 \pm 0.1$ & $5.2 \pm 0.1$ & $5.4 \pm 0.1$ & $5.5 \pm 0.1$ & $5.4 \pm 0.1$ \\
\hline
\end{tabular}

${ }^{*} \mathrm{P}<0.05, \uparrow \mathrm{P}<0.01, \ddagger \mathrm{P}<0.001 ;$ significant change from postinduction value

dopamine postoperatively. Simple and multiple regression procedures were used to assess the relations of the changes in pulmonary diastolic pressure gradient to the corresponding changes in PVR and HR. Significance was assumed at $p$ values less than 0.05 . The results are expressed as means \pm SEM.

\section{Results}

Systemic and pulmonary arterial pressures as well as CO decreased significantly after induction of anaesthesia (Table). However, no significant changes were found in PVR and DPAP-PCWP gradient at this stage of the study.

The haemodynamic data obtained at the three measurement points after CPB were compared with the postinduction values. DPAP was significantly increased after $\mathrm{CPB}$, whereas the increase in PCWP was smaller and reached statistical significance only at the last measurement point. This difference gave rise to a significant increase in DPAP-PCWP gradient (Table). A gradient of $5 \mathrm{mmHg}$ or greater was observed in 16 patients after CPB, whereas none of the patients showed such a gradient before CPB. PVR also increased significantly, whereas SVR decreased transiently after CPB. Increases were observed also in mean pulmonary arterial pressure (MPAP), CVP and heart rate (HR). Mean arterial pressure (MAP) initially decreased but reached the postinduction level at the last measurement point.

The correlation between the change in DPAPPCWP gradient and the change in PVR was weak immediately after CPB but improved at the later stages of the study (Figure). Although the relation of the changes seemed to alter over time, the slopes and/or intercepts of the three regression lines did not show statistically significant differences as assessed by ANOVA. The correlations did not deteriorate when the linear effect of the concomitant HR changes was removed with a multivariate regression technique. After this procedure, the $r$-values were $0.42,0.61$ and 0.78 immediately after, $1 \mathrm{hr}$ after and $3 \mathrm{hr}$ after CPB, respectively. We could find no correlation between the change in DPAP-PCWP gradient and the change in HR at the various stages after $C P B$.

Before and after induction of anaesthesia there were no significant differences in the haemodynamic variables between the patients subsequently requiring or not requiring dopamine. After CPB, the only statistically significant difference in the measured variables was the smaller decrease in $\mathrm{CO}$ at one $\mathrm{hr}$ after $\mathrm{CPB}$ in the patients given dopamine $(-0.2 \pm$ 0.3 vs. $-1.1 \pm 0.281 \cdot \mathrm{min}^{-1}, \mathrm{p}=0.044$ ). Due to this difference, the increase in calculated PVR was slightly smaller in patients receiving dopamine $\left(+18.5 \pm 16.0\right.$ vs $+66.1 \pm 14.3$ dyne $\cdot \mathrm{sec} \cdot \mathrm{cm}^{-5}$, $\mathrm{p}=0.036$ ). The increase in DPAP-PCWP gradient, too, tended to be smaller in patients receiving dopamine but the difference between the two groups was not statistically significant.

\section{Discussion}

A significant increase of DPAP-PCWP gradient was observed after $C P B$ in our patients undergoing myocardial revascularisation. It remains to be shown whether this finding applies also to patients 
undergoing valve replacement or those with poor left ventricular function. In any case, our results show that DPAP should not be used as a substitute of PCWP in the early postbypass period without frequent confirmation of the presence of the normal small DPAP-PCWP gradient. The results of Mammana et al. ${ }^{12}$ suggest that PCWP, too, may be an inaccurate estimate of LAP in this period; these authors observed a significant PCWP-LAP gradient until 12 hours after $C P B$ in patients subjected to elective myocardial revascularisation. However, this finding was not confirmed in a recent study. ${ }^{13}$

Increased diastolic pulmonary pressure gradient may be due to a lack of time for pressure equalization across the pulmonary vascular bed during tachycardia or to an increase in PVR ${ }^{7,8}$ Although HR was increased in our patients after CPB, we found no correlation between the increase in $\mathrm{HR}$ and the increase in DPAP-PCWP gradient in the three study periods after CPB. It is therefore probable that the increased gradient was mainly due to an increase in PVR. The relatively weak correlation between the changes in DPAP-PCWP gradient and in PVR in the first two study periods after CPB is difficult to explain but might be due to the inaccuracy of the usual PVR determination in reflecting the true resistance to flow in the pulmonary circulation. ${ }^{8,14}$ Enson has suggested this resistance is better characterized by the level of the diastolic pressure gradient. $^{8}$

Hypercapnia as a cause of pulmonary vasoconstriction ${ }^{8}$ was excluded in our patients. Although our patients did not show hypoxaemia, an increased hypoxic pulmonary vasoconstriction may have been present after CPB. This assumption is supported by the findings of Anjou-Lindskog et al.,${ }^{15}$ who demonstrated an increased proportion of lung areas with low ventilation/perfusion ratios after myocardial revascularisation and observed a decrease in PVR in these patients after the administration of 100 per cent oxygen (our patients received 50 per cent oxygen after $\mathrm{CPB}$ ).

Canada and Benumof ${ }^{16}$ have shown that, in normal and abnormal dog lungs, PVR and DPAPLAP gradient are smaller at $5 \mathrm{mmHg}$ end-expiratory pressure than zero end-expiratory pressure. It is therefore probable that the $5 \mathrm{cmH}_{2} \mathrm{O}$ end-expiratory pressure applied in our patients after CPB can not explain the increased PVR and DPAP-PCWP gradient.

Rapid administration of protamine $e^{17,18}$ and rapid

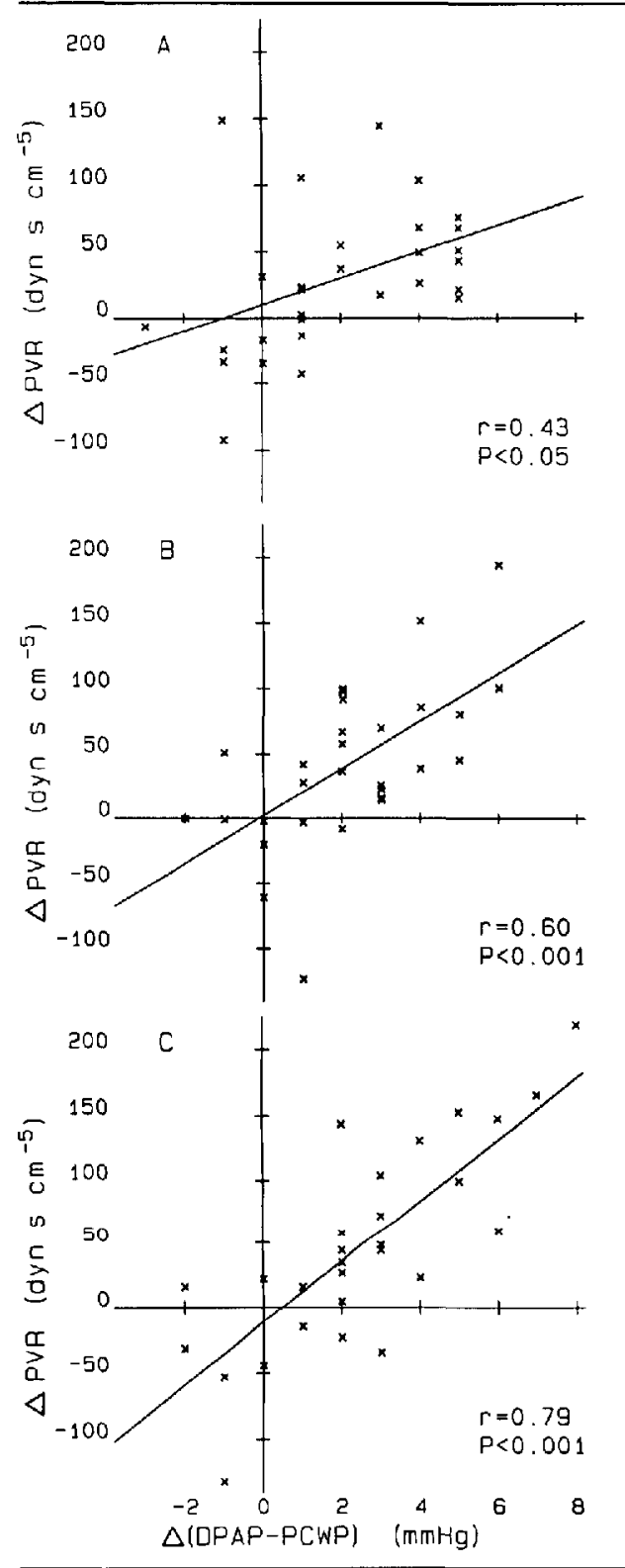

FIGURE Regression lines indicating the correlation between the changes in pulmonary vascular resistance and diastolic pulmonary arterial pressure-pulmonary capillary wedge pressure gradient (DPAP-PCWP) in 29 patients at various stages after cardiopulmonary bypass (CPB). (A) Immediately after CPB; $\triangle P V R=10.04 \times \triangle($ DPAP-PCWP $)+9.54$. (B) 1 hour after $C P B ; \triangle P V R=18.36 \times \triangle(D P A P-P C W P)+1.63$. (C) 3 hour after $C P B ; \triangle P V R=23.73 \times \triangle(D P A P-P C W P)-$ 11.55 . 
blood transfusion ${ }^{2}$ may induce pulmonary vasoconstriction. Both of these factors may have contributed to the development of increased PVR at the time of the first measurement after $\mathrm{CPB}$. However, during the later measurement periods, blood was transfused only slowly and it is unlikely, although not proven, that the haemodynamic effects of protamine extend beyond the immediate postbypass period.

In the presence of $\beta$-adrenergic blockade, catecholamines may induce pulmonary vasoconstriction. ${ }^{19}$ Although most of our patients were taking a $\beta$-blocking drug, it is probable that only little residual effect of the drug was present at the end of CPB. ${ }^{20}$ This should diminish the significance of postoperative catecholaminaemia ${ }^{21}$ as an aetiologic factor in the development of pulmonary vasoconstriction. Dopamine was administered to over half of our patients after CPB. Before $\mathrm{CPB}$, these patients were haemodynamically indistinguishable from those not requiring dopamine, and after CPB the haemodynamic differences were small. In fact, the increase in PVR after CPB was less in patients receiving dopamine and the increase in DPAPPCWP, too, tended to be smaller in this patient group.

The extracorporeal circuit with its direct gasblood interface of the bubble oxygenator has been shown to activate complement and cause pulmonary vascular sequestration of leucocytes. ${ }^{22}$ This provides one plausible explanation to the increase of PVR in our patients. Byrick and Noble, ${ }^{23}$ too, have observed a temporary increase of PVR in patients who underwent aortocoronary bypass with a bubble oxygenator but not in those with membrane oxygenation.

In conclusion, end-diastolic pulmonary arterial pressure should not be used as a substitute of pulmonary capillary wedge pressure in the early postbypass period without frequent confirmation of the presence of the normal small DPAP-PCWP gradient. Several factors may induce an increase in pulmonary vascular resistance after cardiopulmonary bypass and this haemodynamic disturbance is easily diagnosed by finding an increase in DPAP-PCWP gradient. The increase in PVR observed in our patients was small or moderate and was not accompanied with any obvious deterioration in circulation. However, our own clinical experiences and those of others ${ }^{17}$ indicate that a more marked increase of PVR may impair right ventricular ejection and be poorly tolerated in patients with a borderline right ventricular failure. Therefore, we recommend the routine measurement of DPAP-PCWP gradient in the postbypass period.

\section{References}

1 Fitzatrick GF, Hampson LG, Burgess JH. Bedside determination of left atrial pressure. Can Med Assoc J 1972; 102: 1293-8.

2 Lappas D, Lell WA, Gabel JC, Civetra JM, Lowenstein $E$. Indirect measurement of left-atrial pressure in surgical patients. Pulmonary-capillary wedge and pulmonary-artery diastolic pressures compared with left-atrial pressure. Anesthesiology 1973; 38: 394-7.

3 Humphrey $C B$, Oury $J H$, Virgilio $R W$ et al. An analysis of direct and indirect measurements of left atrial filling pressure. J Thorac Cardiovasc Surg 1976; 71: 643-7.

4 Oldham HN, Wechsler AS, Wolfe WG, Anderson $R W$, Sabiston $D C J r$. Left ventricular filling pressure after aorto-coronary grafting. J Thorac Cardiovasc Surg 1973; 65: 343-50.

5 Yelderman $M$, New $W J r$, Rosenthal $M$, Ream $A$. Improved clinical measurement of pulmonary vascular resistance. Anesthesiology 1980; 52: 365-9.

6 Buchbinder N, Ganz W. Hemodynamic monitoring: Invasive techniques. Anesthesiology 1976; 45: 146-55.

7 Enson Y, Wood JA, Mamaras NB. Harvey RM. The influence of heart rate on pulmonary arterial-left ventricular pressure relationships at end-diastole. Circulation 1977; 56: 533-9.

8 Enson $Y$. A survey of pulmonary hemodynamics: structure and function in the central circulation. In: Haemodynamic Changes in Anaesthesia. Volume 1. Vth European Congress of Anaesthesiology. Paris, 1978.

9 Byrick RJ, Kay JC, Noble WH. Extravascular lung water accumulation in patients following coronary artery surgery. Can Anaesth Soc J 1977; 24: 332-45.

10 Ream AK, Reitz BA. Silverberg $G$. Temperature correction of $\mathrm{PCO}_{2}$ and $\mathrm{pH}$ in estimating acid-base status: An example of the emperor's new clathes? Anesthesiology 1982; 56: 41-4.

11 Dixon WJ. BMDP Statistical Software 1981, Department of Biomathematics. Berkeley; University of California Press, 1981.

12 Mammana RB, Hiro S, Levitsky S, Thomas $P A$, 
Plachetka J. Inaccuracy of pulmonary capillary wedge pressure when compared to left atrial pressure in the early postsurgical period. J Thorac Cardiovasc Surg 1982; 84: 420-5.

13 Hessel I/ EA, Bazaral MG, Stewart R, Estafanous $F G$. Pulmonary artery wedge pressure compared to left atrial pressure in cardiac surgical patients. Anesthesiology 1984; 61: A71.

14 Foëx $P$. Pulmonary haemodynamics. In: The Circulation in Anaesthesia. Applied Physiology and Pharmacology. Ed. C Prys-Roberts. Oxford: Blackwell Scientific Publications, 1980.

15 Anjou-Lindskog E, Broman L, Broman $M$, Holmgren A. Effects of oxygen on central haemodynamics and $\dot{\mathrm{V}}_{\mathrm{A}} / \mathrm{Q}$ distribution after coronary bypass surgery. Acta Anaesthesiol Scand 1983; 27 : 378-84.

16 Canada ED, Benumof $J L$. Pulmonary vascular resistance and Ppad-Pla gradients. Anesthesiology 1980; 53: S127.

17 Jastrzebski J, Sykes MK, Woods DG. Cardiorespiratory effects of protamine after cardiopulmonary bypass in man. Thorax 1974; 29: 534-8.

18 Lowenstein E, Johnston WE, Lappas DG et al. Catastrophic pulmonary vasoconstriction associated with protamine reversal of heparin. Anesthesiology 1983; 59: 470-3.

19 Bergofsky EH. Neurohumoral regulation of the pulmonary circulation in health and disease: special role of the adrenergic system. In: Haemodynamic Changes in Anaesthesia. Volume 1. Vth European Congress of Anesthesiology. Paris, 1978.

20 Zimmerman BL. Pharmacologic interventions during cardiopulmonary bypass. In: Pathophysiology and Techniques of Cardiopulmonary Bypass. Ed. JR Utley, EA Ashleigh. Baltimore: Williams \& Wilkins, 1982.

21 Pratilas V, Pratila MG, Vlachakis ND, Owiz $S$, Dimich I. Sympathetic nervous system tonicity and post-coronary artery bypass hypertension. Acta Anaesthesiol Scand 1980; 24: 69-73.

22 Chenoweth DE, Cooper SW, Hugli TE, Stewart RW, Blackstone EH, Kirklin JW. Complement activation during cardiopulmonary bypass. Evidence for generation of $\mathrm{C} 3 \mathrm{a}$ and $\mathrm{C5a}$ anaphylatoxins. $\mathrm{N}$ Engl J Med 1981; 304: 497-503.

23 Byrick RJ, Nobel WH. Postperfusion lung syndrome. Comparison of Travenol bubble and membrane oxygenators. J Thorac Cardiovasc Surg 1978; 76: 685-93.

\section{Résumé}

Chez 29 patients subissant un pontage aorto-coronarien électif. le gradient entre la pression diastolique de l'artère pulmonaire et la pression capillaire pulmonaire (DPAP-PCWP) ainsi que d'autres paramètres hémodynamiques ont été étudiés avant et après induction d'anesthésie, immédiatement après la circulation extracorporelle $(C P B)$ et une heure et trois heures après la circulation extracorporelle. Le gradient DPAP-PCWP est resté inchangè après l'induction mais était significativement augmenté après circulation extracorporelle. Un gradient de $5 \mathrm{mmHg}$ ou plus a été observé chez 16 patients après CEC alors qu'aucun des patients n'a démontré un tel gradiem avant la CEC. Une corrélation significative a été trouvée entre le changement du DPAPPCWP et le changement de ta résistance vasculaire pulmonaire ( $P V R$ ). On conclut que la DPAP ne doit pas être utilisée comme un substitut à la PCWP dans la période précoce après la CEC sans confirmation fréquente de la présence d'un gradient DPAP-PCWP normalement minime. Etant donné que l' augmentation de la résistance vasculaire pulmonaire PVR peut altérer la fraction d'éjection du ventricule droit, on recommande de routine la mesure du gradien DPAP-PCWP en période post-CEC. 